\title{
No association between the rs 10503253 polymorphism in the CSMD1 gene and schizophrenia in a Han Chinese population
}

\author{
Yansong Liu', Zaohuo Cheng ${ }^{2}$, Jun Wang ${ }^{2}$, Chunhui Jin², Jianmin Yuan², Guoqiang Wang ${ }^{2}$, Fuquan Zhang ${ }^{2 *}$ \\ and Xudong Zhao ${ }^{1 *}$
}

\begin{abstract}
Background: Schizophrenia (SCZ) is a complex, heritable, and devastating psychiatric disorder. Recent genome-wide association studies have identified a single-nucleotide polymorphism (SNP; rs10503253) in the CUB and SUSHI multiple domains 1 (CSMD1) gene as a risk factor for SCZ. In this study, we investigated whether the rs10503253 in CSMD1 contributes to the risk of SCZ in a Han Chinese population.

Methods: We conducted a case-control study in a population from eastern China, involving 1378 SCZ patients and 1091 unrelated healthy controls, using the ligase detection reaction-polymerase chain reaction method to genotype the rs10503253 polymorphism in the CSMD1 gene.

Results: No significant association was found between the SCZ patients and controls for any allele or genotype frequency of the SNP rs10503253 (all $P>0.05$ ).

Conclusions: Our findings do not support an association between CSMD1 rs10503253 and SCZ in a Han Chinese population.
\end{abstract}

Keywords: Schizophrenia, CSMD1, rs10503253

\section{Background}

Schizophrenia (SCZ) is a common and heritable psychiatric disorder that affects approximately $1 \%$ of the general population worldwide, characterized by hallucinations, delusions and cognitive deficits, and incompatibility of mental activity and environment. Although genetic factors account for more than $80 \%$ of the etiology and heritability of SCZ, the exact etiology and genetic mechanism of the disease are still unknown $[1,2]$.

The CUB and Sushi multiple domains-1 (CSMD1) gene, located on $8 \mathrm{p} 23.2$, is a complement control-related protein, and CSMD1 is highly expressed in the central nervous system (CNS) [3]. Although the exact functions of this gene remain unclear, it has been reported that CSMD1 may play an important role in modulating the ratio between dopamine and serotonin metabolites in

\footnotetext{
*Correspondence: zhangfa@njmu.edu.cn; zhaoxd@tongji.edu.cn

${ }^{2}$ Wuxi Mental Health Center, Wuxi 214151, Jiangsu Province, China

'Department of Psychosomatic Medicine, Shanghai East Hospital, Tongji University School of Medicine, Shanghai 200092, China
}

CNS [4]. Recently, a single-nucleotide polymorphism (SNP) of CSMD1, rs10503253, has been identified by a large-scale genome-wide association study (GWAS) in samples of European ancestry as a risk genetic variant for SCZ [5]. Subsequent studies have replicated the association of rs 10503253 with SCZ in subjects of European ancestry $[6,7]$. This association was recently confirmed in an enlarged GWAS [8] by the group [5].

The CSMD1 gene has been validated as a target of miR-137 [9], which is involved in regulation adult neurogenesis [10] and neuron maturation [11], and is related to the pathogenesis of SCZ. In addition, several studies have revealed that the A allele of rs10503253 is associated with cognitive dysfunction, which has been documented as a primary and core deficit of $\mathrm{SCZ}[7,12]$. Therefore, CSMD1 is considered to be an important susceptibility gene for SCZ.

Although several studies supported the association of CSMD1 rs10503253 with SCZ, Ohi et al. [13] failed to replicate this result in samples from Japanese descent. 
Given that different ethnic populations may exhibit genetic heterogeneity of SCZ and only several genes have been consistently associated with SCZ across multiple studies in different genetic populations, it is necessary to investigate the possible relationship between this genetic locus and SCZ among other independent populations.

To further evaluate the association of CSMD1 rs10503253 with SCZ, we conducted a case-control study in an independent Han Chinese population from Jiangsu province.

\section{Methods}

\section{Subject recruitment}

The study sample included 1378 patients with SCZ (854 males and 524 females; mean age $=45.92$ years at recruitment, standard deviation $(\mathrm{SD})=11.51)$ and 1091 matched unrelated healthy controls (607 males and 484 females; mean age $=45.01$ years at recruitment, $\mathrm{SD}=$ 10.31), drawn from a population of people of Han descent (Table 1).

For the patient group, the diagnosis of SCZ was confirmed by at least two experienced psychiatrists according to the Structured Clinical Interview for DSM-IV (SCID-I) and the Diagnostic and Statistical Manual of Mental Disorders (DSM-IV) criteria for SCZ. Exclusion criteria included the presence of other mental disorders, neurodevelopmental disorders or significant organic brain injury, epilepsy, and alcohol addiction or substance abuse. For the selection of control subjects, the Structured Clinical Interview for DSM-IV and Non-patients edition (SCID-NP) were used to interview members of an unrelated healthy general population, and those who met any psychiatric diagnosis within the SCID-I Axis I

Table 1 Demographic characteristics of the study subjects

\begin{tabular}{lll}
\hline Group & Case $(n, \%)$ & Control $(\mathrm{n}, \%)$ \\
\hline Sex & & 1091 \\
Total & 1378 & $607(56)$ \\
M & $854(62)$ & $484(44)$ \\
F & $524(38)$ & \\
Age & & $16-77$ \\
Range & $14-76$ & $45.01 \pm 10.31$ \\
Mean & $45.92 \pm 11.51$ & $4(0)$ \\
$14-19$ & $10(1)$ & $97(9)$ \\
$20-29$ & $141(10)$ & $174(16)$ \\
$30-39$ & $201(15)$ & $455(42)$ \\
$40-49$ & $489(35)$ & $275(25)$ \\
$50-59$ & $375(27)$ & $80(7)$ \\
$60-69$ & $151(11)$ & $6(1)$ \\
$70-76$ & $11(1)$ & \\
\hline
\end{tabular}

$M$ Male, $F$ Female were excluded. Subjects with any family history of psychiatric disease among first-degree relatives were also excluded. The control subjects lived in the same geographical area as the patients, and were group matched to the patients by age, gender, and ethnicity. Any subject not born in Jiangsu was excluded, based on a selfreported questionnaire regarding the ancestral and origin birth places.

The clinical research was in compliance with the World Medical Association Declaration of Helsinki-Ethical Principles for Medical Research Involving Human Subjects. This study was approved by the Ethics Committees of the Wuxi Health Mental Center, and signed informed consent was obtained from all participants, or from his/her guardians when the participant had no capacity to consent. Healthy subjects were recruited by advertisement. Before being enrolled in the present study, each subject was also required to sign a consent form.

\section{DNA extraction and SNP genotyping}

Peripheral blood samples were collected from all subjects using $\mathrm{K}_{2}$ EDTA tubes. Genomic DNA was extracted from $150 \mu \mathrm{l}$ of peripheral blood using a blood genotyping DNA extraction kit (Tiangen Biotech, Beijing, China). DNA samples were then stored at $-80{ }^{\circ} \mathrm{C}$ for genotype analysis.

SNP genotyping was performed using the ligase detection reaction-polymerase chain reaction (LDR-PCR) method $[14,15]$ by the Shanghai Biowing Applied Biotechnology Co., Ltd. (www.biowing.com.cn). Genomic DNA extracted from the clinical samples was first subjected to multiplex PCR to obtain a PCR product including SNPs. The PCR primers for SNP rs 10503253 were 5'-CATAAGTTTATATTTCTCAC-3' (forward) and 5'CTGTAGCAGGTTCAACAGAC-3' (reverse). This PCR product and the LDR probes were then subjected to a multiplex LDR reaction, with a DNA sequencer used to detect the products.

\section{Statistical analysis}

All statistical analyses were performed using the online software platform SHEsis (http://analysis.bio-x.cn/myAnalysis.php) [16], including association studies, HardyWeinberg equilibrium (HWE) tests, and the calculation of genotype and allele frequencies between patients with SCZ and healthy controls. The power analysis for our sample size was performed using the $G^{*}$ power analysis program [17] based on Cohen's method [18]. $P$ values of less than 0.05 were considered statistically significant.

\section{Results}

Data from 1378 patients with SCZ and 1091 unrelated healthy controls were analyzed. HWE tests indicated 
that the genotype frequency distribution of rs10503253 did not significantly deviate from HWE $(P=0.15$ for cases; $P=0.35$ for controls). The total genotyping rate in all individuals was $99.51 \%$. In addition, we calculated the power of this study using the G* power program described by $\mathrm{Li}$ et al [19]. The results showed that our sample size revealed $99.87 \%$ power to detect a significant association $(\alpha<0.05)$ when an effect size index of 0.1 (corresponding to a weak gene effect) was used. When an effect size index of 0.2 , which corresponds to a weak to moderate gene effect was used, the sample size showed $100 \%$ power in detecting a significant $(a<0.05)$ allele and genotype association.

The results of our association study suggested that the A allele of SNP rs10503253 within CSMD1 was not significantly associated with SCZ risk $(P=0.26, O R=1.07$, 95 \% CI: 0.95-1.21) in a Han Chinese population sample (see Table 2). Furthermore, stratification analysis by gender did not show any positive association between SCZ and the A allele of SNP rs10503253. A detailed summary is shown in Table 3. The statistical results suggest that the A allele of SNP rs10503253 in CSMD1 might not be a risk locus for SCZ susceptibility in Han Chinese populations.

\section{Discussion}

Previous studies have indicated that the activity of complement components (including complement component C3) is tightly controlled in the brain [20], and deregulation of complement has been found to be involved in psychiatric disorders such as SCZ $[21,22]$. CSMD1 is a complement control-related protein and plays a role in inhibition of complement C3 activation [23, 24]. In addition, it has been reported that CSMD1 is under the control of miR-137 [9], which is implicated in the regulation of adult neurogenesis [10] and neuron maturation [11], and is therefore related to the pathogenesis of SCZ. Furthermore, the CSMD1 gene has been reported to be associated with cognitive dysfunction, which has been recognized as a primary deficit in SCZ $[7,12]$. These results suggest that the CSMD1 gene could be an important factor for SCZ.

Recent GWASs have identified the A allele of SNP rs10503253 as a risk allele for SCZ [5-8]. However, Ohi et al. [13] failed to replicate the association between rs10503253 and SCZ. In our dataset, we also did not detect the association of rs 10503253 with SCZ in a Han Chinese population. This inconsistency might result from the different genetic backgrounds. In the current study, the Han Chinese samples were all recruited from the Jiangsu province of China, the participants in the study by Ohi et al. [13] were people of Japanese descent, while the study samples in the studies by Ripke et al. [5] and Cross-Disorder Group of the Psychiatric Genomics Consortium [6] were all individuals of European ancestry. Furthermore, the samples in the study by Ripke et al. [8] were cohorts of admixed ethnicities from European and East Asian ancestry. The A allele frequencies of the rs10503253 SNP of CSMD1 in healthy controls from our study and the studies by Ohi et al. [13], Ripke et al. [5], Cross-Disorder Group of the Psychiatric Genomics Consortium [6] and Ripke et al. [8] were $0.30,0.32,0.19,0.20$ and 0.22 , respectively. The differences in the CSMD1 polymorphism profiles suggest that populations from different ethnicities might exhibit genetic heterogeneity of SCZ. Additionally, sampling errors caused by differences in clinical diagnosis of SCZ might also contribute to the inconsistency.

There are some limitations to the interpretation of our results. First, in this study we only investigated the SNP rs10503252 in the CSMD1 gene. Other SNPs across the CSMD1 gene may be linked with SCZ and cause alterations in Han Chinese populations. Second, the Han Chinese participants in this study were all recruited from Jiangsu Province, and Han Chinese populations from different geographical areas might also exhibit genetic heterogeneity of SCZ. It is therefore unlikely that our findings can be extended to all people of Han descent. Third, the sample size of our study is still relatively small compared with current large-scale genetic studies $[5,6,8]$, and the association of CSMD1 with SCZ needs to be tested in more samples.

\section{Conclusions}

In summary, this case-control study in a Han Chinese population did not support the association of CSMD1 rs10503252 with SCZ risk, as reported in earlier GWASs studies. We hope that this finding contributes to a better

Table 2 Frequencies of alleles and genotypes for rs 10503253 in SCZ patients and controls

\begin{tabular}{|c|c|c|c|c|c|c|c|c|c|c|}
\hline \multirow[t]{2}{*}{ Group } & \multirow[t]{2}{*}{$n$} & \multicolumn{2}{|l|}{ Allele } & \multirow[t]{2}{*}{$P$} & \multirow[t]{2}{*}{ OR $(95 \% \mathrm{Cl})$} & \multicolumn{3}{|l|}{ genotype } & \multirow[t]{2}{*}{$P$} & \multirow[t]{2}{*}{ HWE } \\
\hline & & $A(n, \%)$ & $C(n, \%)$ & & & $\mathrm{A} / \mathrm{A}(\mathrm{n}, \%)$ & $\mathrm{A} / \mathrm{C}(\mathrm{n}, \%)$ & $C / C(n, \%)$ & & \\
\hline Case & 1378 & 861 (31) & 1895 (69) & 0.26 & $1.07(0.95-1.21)$ & $123(9)$ & $615(45)$ & $640(46)$ & 0.50 & 0. \\
\hline Control & 1091 & $649(30)$ & $1533(70)$ & & & $90(8)$ & $469(43)$ & $532(49)$ & & 0. \\
\hline
\end{tabular}

OR Odds Ratio, $95 \%$ Cl 95 \% Confidence Interval, HWE Hardy-Weinberg equilibrium 
Table 3 Frequencies of alleles and genotypes for rs10503253 in gender groups

\begin{tabular}{|c|c|c|c|c|c|c|c|c|c|}
\hline \multirow[t]{2}{*}{ Group } & \multirow[t]{2}{*}{$n$} & \multicolumn{2}{|l|}{ Allele } & \multirow[t]{2}{*}{$P$} & \multirow[t]{2}{*}{ OR $(95 \% \mathrm{Cl})$} & \multicolumn{3}{|l|}{ genotype } & \multirow[t]{2}{*}{$P$} \\
\hline & & $A(n, \%)$ & $C(n, \%)$ & & & $\mathrm{A} / \mathrm{A}(\mathrm{n}, \%)$ & $\mathrm{A} / \mathrm{C}(\mathrm{n}, \%)$ & $C / C(n, \%)$ & \\
\hline M-case & 854 & $520(30)$ & $1188(70)$ & 0.90 & $1.01(0.86-1.19)$ & $74(9)$ & $372(43)$ & $408(48)$ & 0.76 \\
\hline M-control & 607 & $367(30)$ & $847(70)$ & & & $47(8)$ & $273(45)$ & $287(47)$ & \\
\hline F-case & 524 & 341 (33) & 707 (67) & 0.10 & $1.17(0.97-1.42)$ & $49(10)$ & $243(46)$ & $232(44)$ & 0.12 \\
\hline F-control & 484 & $282(29)$ & $686(71)$ & & & $43(9)$ & $196(40)$ & $245(51)$ & \\
\hline
\end{tabular}

$M$ Male, $F$ Female

understanding of the relationship between CSMD1 genetic variants and SCZ pathogenesis. However, other SNPs within CSMD1 are still possible risk SNPs for SCZ susceptibility, and further research could focus on finding other potential risk variants within CSMD1 for SCZ.

\section{Abbreviations \\ Cl, confidence interval; CSMD1, CUB and SUSHI multiple domains 1; DSM-IV Diagnostic and Statistical Manual of Mental Disorders, 4th edition; F, female; GWASs, genome-wide association studies; HWE, Hardy-Weinberg equilibrium; M, male; OR, odds ratio; PCR, polymerase chain reaction; $S C Z$, schizophrenia; SNP, single-nucleotide polymorphism}

\section{Acknowledgments}

The authors thank all participants for their cooperation in our study.

\section{Funding}

This study was supported by grants from the National Natural Science Foundation of China (81471364). The funding body had no role in the study design; in collection, analysis, and interpretation of data; and in writing the manuscript.

\section{Availability of data and materials}

For access to the data in this paper, interested researchers may contact the corresponding author via email: zhangfa@njmu.edu.cn.

\section{Authors' contributions}

$F Z, Y L, X Z$ designed the study. YL, FZ, ZC, JW, CJ, MY, GW performed the data collection and YL, FZ, ZC, JW, CJ, XZ performed data analyses. YL and $\mathrm{FZ}$ were responsible for manuscript writing. All the authors contributed to discuss the results. And all authors read and approved the final manuscript.

\section{Competing interests}

The authors declare no conflicts of interest

\section{Consent for publication}

Not applicable.

\section{Ethics approval and consent to participate}

This study was approved by the Ethics Committees of the Wuxi Health Mental Center. All participants signed a written informed consent prior to participation in the study.

Received: 29 October 2015 Accepted: 15 June 2016 Published online: 04 July 2016

\section{References}

1. Lichtenstein P, Yip BH, Björk C, Pawitan Y, Cannon TD, Sullivan PF, Hultman CM. Common genetic determinants of schizophrenia and bipolar disorder in Swedish families: a population-based study. Lancet. 2009;373(9659):234-9.

2. Sullivan PF, Kendler KS, Neale MC. Schizophrenia as a complex trait: evidence from a meta-analysis of twin studies. Arch Gen Psychiatry. 2003; 60(12):1187-92.
3. Steen VM, Nepal C, Ersland KM, Holdhus R, Nævdal M, Ratvik SM, Skrede S, Havik B. Neuropsychological deficits in mice depleted of the schizophrenia susceptibility Gene CSMD1. PLoS One. 2013;8(11):e79501.

4. Luykx JJ, Bakker SC, Lentjes E, Neeleman M, Strengman E, Mentink L, DeYoung J, de Jong S, Sul JH, Eskin E, et al. Genome-wide association study of monoamine metabolite levels in human cerebrospinal fluid. Mol Psychiatr. 2013;19(2):228-34.

5. Ripke S, Sanders AR, Kendler KS, Levinson DF, Sklar P, Holmans PA, Lin D, Duan J, Ophoff RA, Andreassen OA, et al. Genome-wide association study identifies five new schizophrenia loci. Nat Genet. 2011:43(10):969-76.

6. Consortium CGOT. Identification of risk loci with shared effects on five major psychiatric disorders: a genome-wide analysis. Lancet. 2013;381(9875): 1371-9.

7. Donohoe G, Walters J, Hargreaves A, Rose EJ, Morris DW, Fahey C, Bellini S, Cummins E, Giegling I, Hartmann AM, et al. Neuropsychological effects of the CSMD1 genome-wide associated schizophrenia risk variant rs 10503253. Genes Brain Behav. 2013:12(2):203-9.

8. Ripke S, Neale BM, Corvin A, Walters JTR, Farh K, Holmans PA, Lee P, BulikSullivan B, Collier DA, Huang $H$, et al. Biological insights from 108 schizophrenia-associated genetic loci. Nature. 2014;511(7510):421-7.

9. Kwon E, Wang W, Tsai L. Validation of schizophrenia-associated genes CSMD1, C10orf26, CACNA1C and TCF4 as miR-137 targets. Mol Psychiatr. 2011;18(1):11-2

10. Szulwach KE, Li X, Smrt RD, Li Y, Luo Y, Lin L, Santistevan NJ, Li W, Zhao X, Jin P. Cross talk between microRNA and epigenetic regulation in adult neurogenesis. J Cell Biol. 2010;189(1):127-41.

11. Smrt RD, Szulwach KE, Pfeiffer RL, Li X, Guo W, Pathania M, Teng Z, Luo Y, Peng J, Bordey A, et al. MicroRNA miR-137 regulates neuronal maturation by targeting ubiquitin ligase mind bomb-1. Stem Cells. 2010;28(6):1060-70.

12. Koiliari E, Roussos P, Pasparakis E, Lencz T, Malhotra A, Siever $\amalg$, Giakoumaki $S G$, Bitsios P. The CSMD1 genome-wide associated schizophrenia risk variant rs 10503253 affects general cognitive ability and executive function in healthy males. Schizophr Res. 2014;154(1-3):42-7.

13. Ohi K, Hashimoto R, Yamamori H, Yasuda Y, Fujimoto M, Umeda-Yano S, Fukunaga M, Watanabe $Y$, Iwase M, Kazui H, et al. The impact of the genome-wide supported variant in the cyclin M2 gene on gray matter morphology in schizophrenia. Behav Brain Funct. 2013;9:40.

14. Shi Y, Li Z, Xu Q, Wang T, Li T, Shen J, Zhang F, Chen J, Zhou G, Ji W, et al. Common variants on 8 p12 and 1q24.2 confer risk of schizophrenia. Nat Genet. 2011;43(12):1224-7.

15. O'Donovan MC, Craddock N, Norton N, Williams H, Peirce T, Moskvina V, Nikolov I, Hamshere M, Carroll L, Georgieva L, et al. Identification of loci associated with schizophrenia by genome-wide association and follow-up. Nat Genet. 2008;40(9):1053-5.

16. Shi YY, He L. SHEsis, a powerful software platform for analyses of linkage disequilibrium, haplotype construction, and genetic association at polymorphism loci. Cell Res. 2005:15(2):97-8.

17. Faul F, Erdfelder E, Lang AG, Buchner A. G*Power 3: a flexible statistical power analysis program for the social, behavioral, and biomedical sciences. Behav Res Methods. 2007;39(2):175-91

18. Cohen J. Statistical power analysis for the behavioral sciences. 2nd ed. Mahway: Lawrence Erlbaum Associates; 1988.

19. Li M, Luo X, Xiao X, Shi L, Liu X, Yin L, Ma X, Yang S, Pu X, Yu J, et al. Analysis of common genetic variants identifies RELN as a risk gene for schizophrenia in Chinese population. World J Biol Psychiatry. 2013;14(2):91-9.

20. Schafer DP, Lehrman EK, Kautzman AG, Koyama R, Mardinly AR, Yamasaki R, Ransohoff RM, Greenberg ME, Barres BA, Stevens B. Microglia sculpt 
postnatal neural circuits in an activity and complement-dependent manner. Neuron. 2012;74(4):691-705.

21. Schafer DP, Lehrman EK, Stevens B. The "quad-partite" synapse: microgliasynapse interactions in the developing and mature CNS. Glia. 2013;61(1):24-36.

22. Havik B, Le Hellard S, Rietschel M, Lybæk H, Djurovic S, Mattheisen M, Mühleisen TW, Degenhardt F, Priebe L, Maier W, et al. The complement control-related genes CSMD1 and CSMD2 associate to schizophrenia. Biol Psychiat. 2011;70(1):35-42.

23. Escudero-Esparza A, Kalchishkova N, Kurbasic E, Jiang WG, Blom AM. The novel complement inhibitor human CUB and Sushi multiple domains 1 (CSMD1) protein promotes factor I-mediated degradation of C4b and C3b and inhibits the membrane attack complex assembly. FASEB J. 2013;27(12): 5083-93.

24. Kraus DM, Elliott GS, Chute H, Horan T, Pfenninger KH, Sanford SD, Foster S, Scully S, Welcher AA, Holers VM. CSMD1 is a novel multiple domain complement-regulatory protein highly expressed in the central nervous system and epithelial tissues. J Immunol. 2006;176(7):4419-30.

Submit your next manuscript to BioMed Central and we will help you at every step:

- We accept pre-submission inquiries

- Our selector tool helps you to find the most relevant journal

- We provide round the clock customer support

- Convenient online submission

- Thorough peer review

- Inclusion in PubMed and all major indexing services

- Maximum visibility for your research

Submit your manuscript at www.biomedcentral.com/submit

) Biomed Central 